\title{
Freeze-thaw decellularization of the trabecular meshwork in an ex vivo eye perfusion model
}

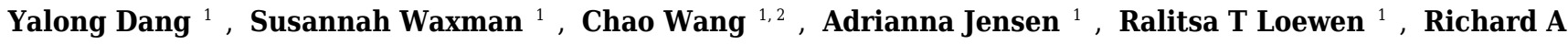 \\ Bilonick $^{1}$, Nils A Loewen ${ }^{\text {Corresp. } 1}$ \\ 1 Department of Ophthalmology, University of Pittsburgh, Pittsburgh, Pennsylvania, United States \\ 2 Department of Ophthalmology, Xiangya School of Medicine, Central South University, Changsha, China \\ Corresponding Author: Nils A Loewen \\ Email address: loewen.nils@gmail.com
}

Objective: The trabecular meshwork (TM) is the primary substrate of outflow resistance in glaucomatous eyes. Repopulating diseased TM with fresh, functional TM cells might be a viable therapeutic approach. Decellularized TM scaffolds have previously been produced by ablating cells with suicide gene therapy or saponin, which risks incomplete cell removal or dissolution of the extracellular matrix, respectively. We hypothesized that improved trabecular meshwork cell ablation would result from freeze-thaw cycles compared to chemical treatment.

Materials and Methods: We obtained 24 porcine eyes from a local abattoir, dissected and mounted them in an anterior segment perfusion within two hours of sacrifice. Intraocular pressure (IOP) was recorded continuously by a pressure transducer system. After 72 hours of IOP stabilization, eight eyes were assigned to freeze-thaw $(\mathrm{F})$ ablation $\left(-80^{\circ} \mathrm{C} \times 2\right)$, to $0.02 \%$ saponin $(\mathrm{S})$ treatment, or the control group (C), respectively. The TM was transduced with an eGFP expressing feline immunodeficiency viral (FIV) vector and tracked via fluorescent microscopy to confirm ablation. Following treatment, the eyes were perfused with standard tissue culture media for 180 hours. TM histology was assessed by hematoxylin and eosin staining. TM viability was evaluated by a calcein AM/propidium iodide (PI) assay. The TM extracellular matrix was stained with Picro Sirius Red. We measured IOP and modeled it with a linear mixed effects model using a B-spline function of time with 5 degrees of freedom.

Results: $\mathrm{F}$ and $\mathrm{S}$ experienced a similar IOP reduction by $30 \%$ from baseline $(\mathrm{P}=0.64)$. IOP reduction of about $30 \%$ occurred in $\mathrm{F}$ within 24 hours and in $\mathrm{S}$ within 48 hours. Live visualization of eGFP demonstrated that $\mathrm{F}$ conferred a complete ablation of all TM cells and only a partial ablation in $\mathrm{S}$. Histological analysis and Picro Sirius staining confirmed that no TM cells survived in $F$ while the extracellular matrix remained. The viability assay showed very low PI and no calcein staining in $\mathrm{F}$ in contrast to many PI-labeled, dead TM cells and calcein-labeled viable TM cells in S.

Conclusion: We developed a rapid TM ablation method that uses cyclic freezing that is free of biological or chemical agents and able to produce a decellularized TM scaffold with preserved TM extracellular matrix in an organotypic perfusion culture. 
1 Freeze-thaw decellularization of the trabecular meshwork in an ex vivo eye perfusion model

4 Yalong Dang ${ }^{1}$, Susannah Waxman ${ }^{1}$, Chao Wang $^{1,2}$, Adrianna D. Jensen $^{1}$, Ralitsa T. Loewen ${ }^{1}$, 5 Richard A. Bilonick ${ }^{1}$, Nils A. Loewen ${ }^{1}$

6 1: Department of Ophthalmology, School of Medicine, University of Pittsburgh, Pittsburgh,

7 United States of America

8 2: Department of Ophthalmology, Xiangya School of Medicine, Central South University,

9 Changsha, China

$10 *$ Corresponding author:

11 Nils A. Loewen, MD, PhD

12203 Lothrop St

13 Suite 819

14 Pittsburgh, PA 15213

15 Email: Loewen.nils@gmail.com

16 Phone: $412-944-2554$ 


\section{Abstract}

18 Objective: The trabecular meshwork (TM) is the primary substrate of outflow resistance in glaucomatous eyes. Repopulating diseased TM with fresh, functional TM cells might be a viable therapeutic approach. Decellularized TM scaffolds have previously been produced by ablating cells with suicide gene therapy or saponin, which risks incomplete cell removal or dissolution of the extracellular matrix, respectively. We hypothesized that improved trabecular meshwork cell ablation would result from freeze-thaw cycles compared to chemical treatment.

Materials and Methods: We obtained 24 porcine eyes from a local abattoir, dissected and mounted them in an anterior segment perfusion within two hours of sacrifice. Intraocular pressure (IOP) was recorded continuously by a pressure transducer system. After 72 hours of IOP stabilization, eight eyes were assigned to freeze-thaw (F) ablation $\left(-80^{\circ} \mathrm{C} \times 2\right)$, to $0.02 \%$ saponin (S) treatment, or the control group (C), respectively. The TM was transduced with an eGFP expressing feline immunodeficiency viral (FIV) vector and tracked via fluorescent microscopy to confirm ablation. Following treatment, the eyes were perfused with standard tissue culture media for 180 hours. TM histology was assessed by hematoxylin and eosin staining. TM viability was evaluated by a calcein AM/propidium iodide (PI) assay. The TM extracellular matrix was stained with Picro Sirius Red. We measured IOP and modeled it with a linear mixed effects model using a B-spline function of time with 5 degrees of freedom.

Results: $F$ and $S$ experienced a similar IOP reduction by $30 \%$ from baseline $(P=0.64)$. IOP reduction of about $30 \%$ occurred in $\mathrm{F}$ within 24 hours and in S within 48 hours. Live visualization of eGFP demonstrated that $\mathrm{F}$ conferred a complete ablation of all TM cells and only a partial ablation in S. Histological analysis and Picro Sirius staining confirmed that no TM cells survived in $F$ while the extracellular matrix remained. The viability assay showed very low PI and no calcein staining in $\mathrm{F}$ in contrast to many PI-labeled, dead TM cells and calcein-labeled viable TM cells in S.

42 Conclusion: We developed a rapid TM ablation method that uses cyclic freezing that is free of biological or chemical agents and able to produce a decellularized TM scaffold with preserved

44 TM extracellular matrix in an organotypic perfusion culture. 
45 Introduction

46 The trabecular meshwork (TM) is the primary substrate of outflow resistance in normal

47 and glaucomatous eyes. Recent studies suggested not only low TM cellularity (Alvarado, Murphy

48 \& Juster, 1984; Baleriola et al., 2008), but also TM cytoskeleton and phagocytosis changes in

49 primary open angle glaucoma (Clark et al., 1995; Fatma et al., 2009; Izzotti et al., 2010; Saccà,

50 Pulliero \& Izzotti, 2015; Peters et al., 2015; Micera et al., 2016). Repopulating diseased TM with

51 fresh, functional TM cells has been shown to restore homeostasis of normal outflow and thus

52 might represent a novel therapeutic breakthrough (Du et al., 2013; Abu-Hassan et al., 2015; Yun

53 et al., 2016; Zhu et al., 2016).

54 For TM cell transplantation studies, preserving the structure and the extracellular matrix

55 are desirable to provide a natural transplantation environment. Eliminating or reducing the

56 number of host TM cells are also useful. In a recent study, an ex vivo 3D bioengineered TM

57 scaffold repopulated by human primary TM cells was developed, but without the distinct layers

58 of juxtacanalicular, corneoscleral and uveal TM (Torrejon et al., 2016). Transgenic (Tg-MYOC

$59 \mathrm{Y437H}$ (Zhu et al., 2016)) and laser photocoagulation mouse models (Yun et al., 2014) have also

60 been used or proposed for TM transplantation, respectively. However, the anatomy of the

61 rodent outflow tract has only a limited number of TM cell layers (three to four) compared to that

62 of humans (Ko \& Tan, 2013). Porcine eyes share many features that are similar to human eyes,

63 including size, structure, intraocular pressure (IOP), the outflow pattern (Sanchez et al., 2011;

64 Loewen et al., 2016e,a) and a large trabecular meshwork that guards the angular aqueous

65 plexus (Tripathi, 1971) with Schlemm's canal-like segments (Suárez \& Vecino, 2006). The

66 presence of biochemical glaucoma markers in the pig (Suárez \& Vecino, 2006), genomic

67 similarities to humans that rival that of mice ("Pairwise Alignment Human vs Pig Blast Results";

68 Groenen et al., 2012; Flicek et al., 2014) and microphysiological properties such as giant vacuole

69 formation Schlemm's canal endothelium (McMenamin \& Steptoe, 1991) suggests pig eyes as

70 glaucoma research models (Ruiz-Ederra et al., 2005).

71 Abu-Hassan et al. used saponin as an elegant way to induce a glaucoma-like dysfunction

72 and cell loss in the TM of pig eyes (Abu-Hassan et al., 2015) with a 36\% $\pm 9 \%$ cell count

73 reduction at 10 minutes. Saponins are a mixed group of plant derived, steroid and terpenoid

74 glycosides that are used as detergents. The impact on remaining host and transplanted donor

75 TM cells as well as on the ECM is not known. To address these concerns, we developed a

76 chemical-free, freeze-thaw method to produce a decellularized TM scaffold. Together with our

77 anterior segment perfusion system (Loewen et al., 2016e), this scaffold model can be used for

78 cell transplantation, allowing real-time TM visualization and IOP measurement. 
79 Materials and methods

\section{Study design}

81 Pig eyes were obtained from a local abattoir and prepared for culture within 2 hours of

82 death. Twenty-four eyes were assigned to three groups: freeze-thaw (F, n=8), saponin (S, $n=8)$

83 and control $(C, n=8)$. This number was chosen based on past power calculations and the

84 maximum number that could be perfused simultaneously thereby minimizing the variability with

85 same group experiments with our setup (Loewen et al., 2016e,a). Anterior segment perfusion

86 cultures were allowed to stabilize for 72 hours before being subjected to freeze-thaw cycles or to

87 saponin supplemented media, respectively. The intraocular pressure (IOP) was recorded

88 continuously by a pressure transducer system (Physiological Pressure Transducer, SP844;

89 MEMSCAP, Skoppum, Norway) (Loewen et al., 2016e,a). Anterior segment cultures were

90 continued for another 180 hours. Two additional eyes per ablation method group were

91 transduced with eGFP expressing feline immunodeficiency viral vectors and subjected to the

92 same ablation methods as used in the experimental groups. Expression of eGFP was monitored

93 and compared. Two eyes per group were randomly selected for TM viability assays, histological

94 analysis, and ECM assessment.

\section{Preparation of porcine anterior segments and perfusion system}

After removing extraocular tissues, freshly enucleated porcine eyes from a local abattoir (Thoma Meat Market, Saxonburg, PA) were placed into a 5\% povidone-iodine solution (NC9771653, Fisher Scientific, Waltham, MA) for 3 minutes and rinsed three times with phosphate-buffered saline (PBS). Eyes were hemisected $7 \mathrm{~mm}$ posterior and parallel to the limbus and the lens, ciliary body, and iris were carefully removed. Anterior segments were again washed with PBS three times and mounted in anterior segment perfusion dishes. Phenol-free DMEM media (SH30284, HyClone, GE Healthcare, UK)) supplemented with $1 \%$ fetal bovine serum and $1 \%$ antibiotic-antimycotic (15240062, Thermo Fisher Scientific, Waltham, MA) was continuously pumped into the anterior chambers at a constant infusion rate of 3 microliters per minute. After calibration of the pressure transducers, the IOP was recorded in 2-minute intervals.

\section{TM ablation by freeze-thaw cycles or $0.02 \%$ saponin}

After allowing the eyes to stabilize for 72 hours, the groups were subjected to freezethaw cycles or $0.02 \%$ saponin, respectively. In the freeze-thaw group, anterior segments were exposed to $-80^{\circ} \mathrm{C}$ for 2 hours, then thawed at room temperature for 1 hour. After two cycles, anterior segments were reconnected to the perfusion system. In the saponin group, the regular perfusion media was replaced with $0.02 \%$ saponin supplemented media for 15 minutes, then exchanged for the normal perfusion media in a $37^{\circ} \mathrm{C}$ incubator as described before (Abu-Hassan et al., 2015). 
Feline immunodeficiency viral vectors expressing eGFP were generated by transient encoding eGFP and neomycin resistance GINSIN (Saenz et al., 2007; Oatts et al., 2013; Zhang et al., 2014) using a polyethylenimine method (Loewen et al., 2016e). Supernatant from 293T transfected cells containing GINSIN vector was harvested at two, four and six days after transfection, then concentrated by ultracentrifugation. $1 \times 10^{7}$ transducing units (TU) of GINSIN were injected into the anterior chambers. eGFP expression was followed through the bottom of the culture dish using a dissecting microscope equipped for epifluorescence (SZX16, Olympus,

TM viability

TM viability was evaluated by calcein acetoxymethyl (calcein AM) and propidium iodide (PI) co-labelling (Gonzalez, Hamm-Alvarez \& Tan, 2013; Dang et al., 2017a). After 180 hours, the anterior segments were collected and washed with PBS three times. The limbus with the TM was dissected and incubated with calcein AM (0.3 $\mu \mathrm{M}, \mathrm{C} 1430$, Thermo Fisher, Waltham, MA) and PI ( $1 \mu \mathrm{g} / \mathrm{ml}, \mathrm{P} 1304 \mathrm{MP}$, Thermo Fisher, Waltham, MA) for $30 \mathrm{~min}$ at $37^{\circ} \mathrm{C}$. After three additional PBS washes, the TM was flat-mounted, and imaged under an upright laser scanning confocal microscope at 400-fold magnification (BX61, Olympus, Tokyo, Japan).

\section{TM histology}

TM samples obtained from at least two separate quadrants per eye were dissected and fixed with 4\% paraformaldehyde in PBS for 24 hours. After rinsing them three times in PBS, they were embedded in paraffin, sectioned at 6-micron thickness and stained with hematoxylin and 137 eosin.

\section{TM-ECM assessment}

The TM-ECM was assessed by a Picro Sirius Red staining protocol as described previously (Pattabiraman et al., 2015). Briefly, the sections were deparaffinized, rehydrated by ethanol gradient and deionized water, then incubated in Picro-Sirius Red Solution (ab150681, Abcam, Cambridge, MA) for 60 minutes. After rinsing the sections quickly in acetic acid solution (ab150681, Abcam, Cambridge, MA), an ethanol dehydration was performed. Pictures were taken with a conventional light microscope using the above settings. The staining intensity of the TM region was scored by a masked reviewer (YD) on a scale from 1 to 4.

\section{Statistics}

Data were presented as the mean \pm standard error and analyzed by PASW 18.0 (SPSS Inc., 
150 Mann-Whitney $U$ test were used to compare the grading of ECM staining. A statistical difference 151 of $p<0.05$ was considered significant. A linear mixed effects model was fitted to the fold change 152 response in R (Core Team, 2016; Dang et al., 2017b). The response was modeled as a B-spline 153 function of time with 5 degrees of freedom (Berk; Hu et al., 1998).

\section{Results}

155 Trabecular meshwork morphology, histology and ECM assessment

156 Two eyes per group were discarded due to leaks while the baseline was established. In eyes that 157 were successfully cultured, the gross morphology of the anterior chambers remained well 158 preserved after two freeze-thaw cycles, with light opacification of the corneas as the most 159 notable change (Fig. 1). Histology from within 24 hours after exposure to freeze-thaw (F) or 160 saponin (S) indicated that F preserved the microarchitecture better (Fig. 2 A and B) than S (Fig. 2 161 C). Blue stained nucleoli could still be observed but disappeared later, consistent with the 162 viability assay results described below. We assessed the TM-ECM (Cormack, 2001; Fischer et al., 1632008 ) by Picro Sirius Red staining. Compared to the normal control (Fig. 3 A), neither freeze164 thaw cycles (Fig. 3 B) nor saponin (Fig. 3 C) caused a significant loss or increase of the total ECM 165 deposition after 180 hours perfusion ( $P=0.324$ and $P=0.095$, respectively; Fig. $3 \mathrm{D}$ ).

\section{Monitoring of TM ablation}

167 Ablation control eyes were transduced with a relatively low titer of $1 \times 10^{7}$ eGFP FIV vectors prior 168 to $\mathrm{F}$ and S. 24 hours after transduction, the TM cells began to express eGFP, reaching a peak 169 intensity at 48 hours, as reported previously (Loewen et al., 2016e; Dang et al., 2016b). There 170 were discontinuous areas of transduced TM (Fig. 4 A, B, E and F) and transduction along corneal 171 stretch folds as well as sclera. Two cycles of $-80^{\circ} \mathrm{C}$ completely abolished eGFP fluorescence (Fig.

$1724 \mathrm{C}$ and D). Two cycles were necessary because pilot eyes with only one cycle still showed some 173 eGFP positive cells. In contrast, after 0.02\% saponin perfusion, eGFP fluorescence appeared 174 quenched, and only a small portion of transduced cells was ablated 24 hours after exposure (Fig. $1754 \mathrm{G}$ and $\mathrm{H})$.

\section{TM viability}

177 Calcein AM and PI staining were used to as a viability assay to validate TM ablation by freeze178 thaw or saponin exposure. Most TM cells from the control group were positive with Calcein AM 179 showing bright green fluorescence (Fig. 5a-Fig. 5c), while only occasionally stained with PI (Fig. 180 5b and Fig. 5c) at the TM depths of $10 \mu \mathrm{m}, 50 \mu \mathrm{m}$ and $100 \mu \mathrm{m}$. In contrast, no Calcein AM 181 staining and very few PI-stained cells were found in the freeze-thaw group (Fig. 5d-Fig. 5f). 182 Different from the above two groups, most of the TM cells in the saponin group were labeled by $183 \mathrm{PI}$, with few cells demonstrating a light calcein AM staining (Fig. 5g-Fig. 5h). 
A stable baseline was established for all anterior segments for 72 hours before exposure to $\mathrm{F}$ or S. IOPs varied insignificantly by $10.3 \pm 7.5 \%$ throughout the end of the study (all $P>0.05$ compared to the baseline) (Fig. 6). However, pressure decreased dramatically after either freeze-thaw or saponin (baseline freeze-thaw $14.75 \pm 2.24 \mathrm{mmHg}$, baseline saponin $14.37 \pm 1.14 \mathrm{mmHg}$, $P=0.288$ ). At 12 hours, $F$ dropped to $70 \pm 7.1 \%$ and $S$ to $79.2 \pm 8.1 \%$ from the baseline, respectively. F remained significantly lower than $C$ for 96 hours $(P=0.02)$, but eye experienced a larger IOP variability onward resulting in reduced significance. In contrast, $S$ had a significantly lower IOP throughout the study until the experimental endpoint at 180 hours. We applied a linear mixed effects model that used a B-spline function of time with 5 degrees of freedom (Berk) (Supplement 1). The results reflect the averages shown in Fig. 5 and confirm the three nonlinear behaviors with distinctly different patterns. $\mathrm{F}$ had an intercept, representative of the initial IOP drop, that was -0.378 fold less ( $p<0.001$ ) than $C$ and a standard error of 0.088 with 15 degrees of freedom and a $\mathrm{t}$-value of -4.3. $\mathrm{F}$ was not significantly different from $\mathrm{S}$ in the B-spline function model $(p=0.142)$. $S$ had an intercept that was 0.242 fold less than $C(p=0.013)$ with a standard error of 0.086 and 15 degrees of freedom.

\section{Discussion}

In this study, we developed a method to decellularize the trabecular meshwork in anterior segment perfusion cultures quickly and reliably. This was achieved with two cycles of freezing at $-80^{\circ} \mathrm{C}$ and thawing at room temperature. This avoids the use of chemical agents that might dissolve the ECM or have other, not well-characterized effects. We compared this method to a saponin-mediated ablation. Each method has distinct properties and advantages. Freezethaw cycles, applied here to group $F$, have been used extensively before to ablate tissues in treatment of human diseases (Erinjeri \& Clark, 2010; Baust et al., 2014; Chu \& Dupuy, 2014) including cyclocryodestruction in glaucoma (Benson \& Nelson, 1990). It has also been used in research (Baust et al., 2014; Chan \& Ooi, 2016; Liu et al., 2016) and in food production ("Fish and Fishery Products Hazards and Controls Guidance"; Gill, 2006; Craig, 2012). Mechanisms of cryoablation in medicine include direct cell injury, vascular injury, ischemia, apoptosis, and immunomodulation (Chu \& Dupuy, 2014): cell injury during freezing causes dehydration from the so-called solution effect that causes the earlier freezing extracellular compartment to extract solutes, an osmotic gradient and cell shrinkage (Lovelock, 1953). This can be enhanced by ice crystal formation within the cell, damaging organelles and the cell membrane. During thawing, the intracellular compartment shifts to hypertonia, attracting fluid that causes the cell to burst. Mechanisms not at work in our model are direct cold-induced coagulative necrosis that is the result of sublethal temperatures that activate apoptosis (Baust \& Gage, 2005) and direct, coldinduced coagulative necrosis from vascular injury as a result of stasis, thrombosis, and ischemia. 
220 An interesting clinical effect is the intense inflammation after cryoablation that is different from

221 heat coagulation as immunogenic epitopes are preserved (Jansen et al., 2010).

222 Saponin, used in experimental group S, can lyse cells. At lower concentrations, it has also 223 been used to reduce the viability of cells (Abu-Hassan et al., 2015). Saponins are an enormously

224 large class of chemical compounds that exist in a range of plant species (Saponaria) which can

225 produce soap-like foam when shaken in aqueous solution and has been used in early soaps

226 (Coombes, 2012). These substances are amphiphilic (both hydro- and lipophilic) glycosides in

227 which a sugar is bound to a functional three-terpene group via a glycosidic bond. Saraponins are

228 an important subset of saponins that are steroidal while aglycone derivatives have the

229 pharmacologic characteristics of alkaloids. Historically, saponins have been used as a poison for

230 fishing (Campbell, 1999). The ability of saponins to form complexes with cholesterol has been

231 exploited for both therapeutic and research purposes. These cholesterol-saponin complexes

232 create pores in the cell membrane, which can enhance the penetration of macromolecules but

233 also induce lysis (Holmes et al., 2015). All of the above properties may have wide-ranging and

234 difficult to characterize effects in cell transplantation models. Additionally, different batches of

235 saponin may have a different composition of compounds. It is, therefore, necessary to

236 determine the proper concentration for saponin with different lot numbers to increase the

237 reproducibility of experiments.

238 The macroscopic appearance of group $\mathrm{F}$ compared to group S samples had only minor

239 differences which consisted of mild opacification of the cornea. The microscopic architecture

240 was well preserved in F, but less so in S. This can be expected based on the properties of these

241 two different methods described above. Especially the change of permeability of cell

242 membranes by saponin might cause edema by allowing fluids to enter the extracellular space

243 more easily compared to freeze-thaw that is more likely to cause dehydration (Mazur, 1963;

244 Mazur, Rall \& Leibo, 1984; Wolkers et al., 2007). Compared to the cells themselves, many blue

245 nuclei persisted in early histology because they are less permeable and contain less fluid

246 compared to the cytoplasm. These observations were reflected in the ablation of transduced,

247 eGFP expressing cells. Freeze-thaw caused nearly complete loss of fluorescence after the first

248 cycle and disappeared entirely when cells were disrupted after the second cycle. Saponin

249 appears to have caused leakage of eGFP proteins were diminished fluorescence was observed,

250 but only a few cells were fully lysed.

251 The results of TM viability assay by Calcein AM/PI staining further confirmed the findings

252 from the histological analysis and eGFP ablation. Freeze-thaw caused the disappearance of

253 almost all cells secondary to the above mechanism of cell dehydration and subsequent burst.

254 Saponin appears to have been a sublethal injury to many cells, especially in the uveal and

255 corneoscleral TM. Abu-Hassan et al. developed a protocol to induce a sublethal injury with

256 saponin to mimic a glaucomatous TM injury in an ex vivo model and were able to correct the 
257 glaucoma phenotype (Abu-Hassan et al., 2015). We observed a modest decline in a model of 258 inducible cytoablation mediated by an HSV-tk suicide vector (Zhang et al., 2014).

This pattern of cell death matches the IOP reduction of groups $\mathrm{F}$ and $\mathrm{S}$. F experienced a

260

261

262

263

264

265

266

267

268

269

270

271

272

273

274

275

276

277

278

279

280

281

282

283

284

285

286

287

288

289

290

291

292

293 more immediate drop compared to $S$ as could be expected by a complete breakdown of the TM outflow regulation. In comparison, the slower downslope seen after saponin exposure likely reflects the more gradual cell function decline with eventual cell death. The final IOP was lower in $\mathrm{S}$ which may represent the loss not only of cells but also of hydrophilic components of the ECM which could persist in eyes in $\mathrm{F}$ to a longer extent and time. $\mathrm{H} \& \mathrm{E}$ and Picrosirius red, used here to obtain a comprehensive characterization of the ECM, do not differentiate between its two main categories, proteoglycans and fibrous proteins, or their subgroups (Frantz, Stewart \& Weaver, 2010). More than the fibrous scaffold of the ECM, hydrogel-like ECM components require a continuous production and have a more fleeting nature. Because of this, timing of of cell seeding in repopulation experiments will be crucial.

Our use of a B-spline function provides a more appropriate description of effects in an eye culture model that play out over a period rather than the common comparison of single time points. Single time point comparisons assume incorrectly that observations are largely unrelated (Hu et al., 1998). Handling longitudinal data with B-spline functions extends the standard linear mixed-effects models and accounts for a broad range of non-linear behaviors (Dang et al., 2017b). B-spline functions are robust to small sample sizes, as well as to noisy observations and missing data.

Consistent with our clinical (Akil et al., 2016; Loewen et al., 2016d; Neiweem et al., 2016; Dang et al., 2016c,a; Kaplowitz et al., 2016; Roy et al., 2017) and laboratory findings (Zhang et al., 2014; Parikh et al., 2016a; Wang et al., 2017), TM ablation improves outflow and lowers IOP. A $20.8 \pm 8.1 \%$ IOP reduction was achieved at 12 hours after saponin treatment and a $30.0 \pm 7.1 \%$ reduction in the freeze-thaw group. The freeze-thaw cycles removed all meshwork cells, including those in the corneoscleral and cribriform TM which account for at least $50 \%$ of trabecular outflow resistance, whereas most of these cells were preserved in the saponin group. It is possible that the IOP reduction seen after cyclocryodestruction is at least partially due to an improvement of conventional outflow and not only due to reduced aqueous humor production or uveoscleral outflow enhancement from inflammation (Gorsler, Thieme \& Meltendorf, 2015).

The limitations of this study are that cytoablation via freeze-thaw may liberate other, undesirable factors from non-trabecular cells that also die. The argument against a profound impact of those is that the macroscopic and microscopic structures were surprisingly stable for the entire time of 10 days. We only describe an ablation method here but not a repopulation of the trabecular meshwork by cell transplantation. Transduction (Loewen et al., 2001, 2002, 2016f) affects high outflow areas more than low flow areas of the eye (Loewen et al., 2016b,c; Parikh et al., 2016b; Dang et al., 2017c) which is the result of a higher multiplicity of infection 
294 (m.o.i., transduction events per cell). We speculate that these areas might also be more affected 295 by saponin but equally ablated by freeze-thaw cycles.

296 In conclusion, we developed a fast, inexpensive and reliable method that results in 297 complete ablation of TM cells while the architecture was well-preserved. 


\section{References}

299 Abu-Hassan DW., Li X., Ryan El., Acott TS., Kelley MJ. 2015. Induced Pluripotent Stem Cells Restore

$300 \quad$ Function in a Human Cell Loss Model of Open-Angle Glaucoma. Stem cells 33:751-761.

301 Akil H., Chopra V., Huang A., Loewen N., Noguchi J., Francis BA. 2016. Clinical Results of Ab Interno

302 Trabeculotomy Using the Trabectome in Patients with Pigmentary Glaucoma compared to Primary

$303 \quad$ Open Angle Glaucoma. Clinical \& experimental ophthalmology. DOI: 10.1111/ceo.12737.

304 Alvarado J., Murphy C., Juster R. 1984. Trabecular meshwork cellularity in primary open-angle glaucoma

305 and nonglaucomatous normals. Ophthalmology 91:564-579.

306 Baleriola J., García-Feijoo J., Martínez-de-la-Casa JM., Fernández-Cruz A., de la Rosa EJ., Fernández-

307 Durango R. 2008. Apoptosis in the trabecular meshwork of glaucomatous patients. Molecular vision

$308 \quad \underline{14: 1513-1516 .}$

309 Baust JG., Gage AA. 2005. The molecular basis of cryosurgery. BJU international 95:1187-1191.

310 Baust JG., Gage AA., Bjerklund Johansen TE., Baust JM. 2014. Mechanisms of cryoablation: clinical

311 consequences on malignant tumors. Cryobiology 68:1-11.

312 Benson MT., Nelson ME. 1990. Cyclocryotherapy: review of cases over 10-year. The British journal of

$313 \quad$ ophthalmology 74:103-105.

314 Berk M. Smoothing-splines Mixed-effects Models in R using the sme Package: a Tutorial.

315 Campbell PD. 1999. Survival Skills of Native California. Gibbs Smith.

316 Chan JY., Ooi EH. 2016. Sensitivity of thermophysiological models of cryoablation to the thermal and

$317 \quad$ biophysical properties of tissues. Cryobiology 73:304-315.

318 Chu KF., Dupuy DE. 2014. Thermal ablation of tumours: biological mechanisms and advances in therapy.

$319 \quad$ Nature reviews. Cancer 14:199-208.

320 Clark AF., Miggans ST., Wilson K., Browder S., McCartney MD. 1995. Cytoskeletal changes in cultured

321 human glaucoma trabecular meshwork cells. Journal of glaucoma 4:183-188. 
322 Coombes AJ. 2012. The A to Z of Plant Names: A Quick Reference Guide to 4000 Garden Plants. Timber

$323 \quad$ Press.

324 Core Team R. 2016. R: A Language and Environment for Statistical Computing. Vienna, Austria: R

$325 \quad$ Foundation for Statistical Computing.

326 Cormack DH. 2001. Essential Histology. Lippincott Williams \& Wilkins.

327 Craig N. 2012. Fish tapeworm and sushi. Canadian family physician Medecin de famille canadien 58:654-

$328 \quad \underline{658}$.

329 Dang Y., Kaplowitz K., Parikh HA., Roy P., Loewen RT., Francis BA., Loewen NA. 2016a. Steroid-induced

330 glaucoma treated with trabecular ablation in a matched comparison to primary open angle

331 glaucoma. Clinical \& experimental ophthalmology. DOI: 10.1111/ceo.12796.

332 Dang Y., Loewen R., Parikh HA., Roy P., Loewen NA. 2016b. Gene transfer to the outflow tract.

333 Experimental eve research:044396.

334 Dang Y., Roy P., Bussel II., Loewen RT., Parikh H., Loewen NA. 2016c. Combined analysis of trabectome

335 and phaco-trabectome outcomes by glaucoma severity. F1000Research 5:762.

336 Dang Y., Waxman S., Wang C., Loewen RT., Sun M., Loewen N. 2017a. Trabecular Meshwork Failure In A

$337 \quad$ Model Of Pigmentary Glaucoma. bioRxiv:118448. DOI: 10.1101/118448.

338 Dang Y., Waxman S., Wang C., Parikh HA., Bussel II., Loewen RT., Xia X., Lathrop KL., Bilonick RA., Loewen

$339 \quad$ NA. 2017b. Rapid learning curve assessment in an ex vivo training system for microincisional

340 glaucoma surgery. Scientific reports 7:1605.

341 Dang Y., Waxman S., Wang C., Parikh HA., Bussel II., Loewen RT., Xia X., Lathrop KL., Bilonick RA., Loewen

$342 \quad$ NA. 2017c. Rapid learning curve assessment in an ex vivo training system for microincisional

343 glaucoma surgery. Scientific reports 7:1605.

344 Du Y., Yun H., Yang E., Schuman JS. 2013. Stem cells from trabecular meshwork home to TM tissue in vivo.

$345 \quad$ Investigative ophthalmology \& visual science 54:1450-1459. 
346 Erinjeri JP., Clark TWI. 2010. Cryoablation: mechanism of action and devices. Journal of vascular and

$347 \quad$ interventional radiology: JVIR 21:S187-91.

348 Fatma N., Kubo E., Toris CB., Stamer WD., Camras CB., Singh DP. 2009. PRDX6 attenuates oxidative stress-

349 and TGF $\beta$-induced abnormalities of human trabecular meshwork cells. Free radical research 43:783-

$350 \quad \underline{795}$.

351 Fischer AH., Jacobson KA., Rose J., Zeller R. 2008. Hematoxylin and eosin staining of tissue and cell $352 \quad$ sections. CSH protocols 2008:db.prot4986.

353 Fish and Fishery Products Hazards and Controls Guidance

354 Flicek P., Amode MR., Barrell D., Beal K., Billis K., Brent S., Carvalho-Silva D., Clapham P., Coates G.,

355 Fitzgerald S., Gil L., Girón CG., Gordon L., Hourlier T., Hunt S., Johnson N., Juettemann T., Kähäri AK.,

356 Keenan S., Kulesha E., Martin FJ., Maurel T., McLaren WM., Murphy DN., Nag R., Overduin B.,

357 Pignatelli M., Pritchard B., Pritchard E., Riat HS., Ruffier M., Sheppard D., Taylor K., Thormann A.,

358 Trevanion SJ., Vullo A., Wilder SP., Wilson M., Zadissa A., Aken BL., Birney E., Cunningham F., Harrow

$359 \quad \underline{\text { J., Herrero J., Hubbard TJP., Kinsella R., Muffato M., Parker A., Spudich G., Yates A., Zerbino DR., }}$

360 Searle SMJ. 2014. Ensembl 2014. Nucleic acids research 42:D749-55.

361 Frantz C., Stewart KM., Weaver VM. 2010. The extracellular matrix at a glance. Journal of cell science.

$362 \quad \underline{123: 4195-4200 .}$

363 Gill CO. 2006. Microbiology of Frozen Foods. In: Handbook of Frozen Food Processing and Packaging.

$364 \quad$ crcnetbase.com, 85-100.

365 Gonzalez JM Jr., Hamm-Alvarez S., Tan JCH. 2013. Analyzing live cellularity in the human trabecular

$366 \quad$ meshwork. Investigative ophthalmology \& visual science 54:1039-1047.

367 Gorsler I., Thieme H., Meltendorf C. 2015. Cyclophotocoagulation and cyclocryocoagulation as primary

368 surgical procedures for open-angle glaucoma. Graefe's archive for clinical and experimental

369 ophthalmology = Albrecht von Graefes Archiv fur klinische und experimentelle Ophthalmologie

$370 \quad \underline{253: 2273-2277 .}$ 
371 Groenen MAM., Archibald AL., Uenishi H., Tuggle CK., Takeuchi Y., Rothschild MF., Rogel-Gaillard C., Park

372 C., Milan D., Megens H-J., Li S., Larkin DM., Kim H., Frantz LAF., Caccamo M., Ahn H., Aken BL.,

373 Anselmo A., Anthon C., Auvil L., Badaoui B., Beattie CW., Bendixen C., Berman D., Blecha F.,

374 Blomberg J., Bolund L., Bosse M., Botti S., Bujie Z., Bystrom M., Capitanu B., Carvalho-Silva D.,

375 Chardon P., Chen C., Cheng R., Choi S-H., Chow W., Clark RC., Clee C., Crooijmans RPMA., Dawson

376 HD., Dehais P., De Sapio F., Dibbits B., Drou N., Du Z-Q., Eversole K., Fadista J., Fairley S., Faraut T.,

377 Faulkner GJ., Fowler KE., Fredholm M., Fritz E., Gilbert JGR., Giuffra E., Gorodkin J., Griffin DK.,

378 Harrow JL., Hayward A., Howe K., Hu Z-L., Humphray SJ., Hunt T., Hornshøj H., Jeon J-T., Jern P., Jones

379 M., Jurka J., Kanamori H., Kapetanovic R., Kim J., Kim J-H., Kim K-W., Kim T-H., Larson G., Lee K., Lee

$380 \quad$ K-T., Leggett R., Lewin HA., Li Y., Liu W., Loveland JE., Lu Y., Lunney JK., Ma J., Madsen O., Mann K.,

381 Matthews L., McLaren S., Morozumi T., Murtaugh MP., Narayan J., Nguyen DT., Ni P., Oh S-J., Onteru

382 S., Panitz F., Park E-W., Park H-S., Pascal G., Paudel Y., Perez-Enciso M., Ramirez-Gonzalez R., Reecy

$383 \quad$ JM., Rodriguez-Zas S., Rohrer GA., Rund L., Sang Y., Schachtschneider K., Schraiber JG., Schwartz J.,

384 Scobie L., Scott C., Searle S., Servin B., Southey BR., Sperber G., Stadler P., Sweedler JV., Tafer H.,

385 Thomsen B., Wali R., Wang J., Wang J., White S., Xu X., Yerle M., Zhang G., Zhang J., Zhang J., Zhao S.,

386 Rogers J., Churcher C., Schook LB. 2012. Analyses of pig genomes provide insight into porcine

387 demography and evolution. Nature 491:393-398.

388 Holmes SE., Bachran C., Fuchs H., Weng A., Melzig MF., Flavell SU., Flavell DJ. 2015. Triterpenoid saponin

389 augmention of saporin-based immunotoxin cytotoxicity for human leukaemia and lymphoma cells is

390 partially immunospecific and target molecule dependent. Immunopharmacology and

$391 \quad$ immunotoxicology 37:42-55.

392 Hu FB., Goldberg J., Hedeker D., Flay BR., Pentz MA. 1998. Comparison of Population-Averaged and

$393 \quad$ Subject-Specific Approaches for Analyzing Repeated Binary Outcomes. American journal of

$394 \quad$ epidemiology 147:694-703. 
395 Izzotti A., Saccà SC., Longobardi M., Cartiglia C. 2010. Mitochondrial damage in the trabecular meshwork

396 of patients with glaucoma. Archives of ophthalmology 128:724-730.

397 Jansen MC., van Hillegersberg R., Schoots IG., Levi M., Beek JF., Crezee H., van Gulik TM. 2010.

398 Cryoablation induces greater inflammatory and coagulative responses than radiofrequency ablation

399 or laser induced thermotherapy in a rat liver model. Surgery 147:686-695.

400 Kaplowitz K., Bussel II., Honkanen R., Schuman JS., Loewen NA. 2016. Review and meta-analysis of ab-

401 interno trabeculectomy outcomes. The British journal of ophthalmology 100:594-600.

402 Ko MK., Tan JCH. 2013. Contractile markers distinguish structures of the mouse aqueous drainage tract.

$403 \quad$ Molecular vision 19:2561-2570.

404 Liu X., Zhao G., Shu Z., Niu D., Zhang Z., Zhou P., Cao Y., Gao D. 2016. Quantification of Intracellular Ice

$405 \quad$ Formation and Recrystallization During Freeze-Thaw Cycles and Their Relationship with the Viability

406 of Pig lliac Endothelium Cells. Biopreservation and biobanking 14:511-519.

407 Loewen N., Bahler C., Teo W-L., Whitwam T., Peretz M., Xu R., Fautsch MP., Johnson DH., Poeschla EM.

$408 \quad$ 2002. Preservation of aqueous outflow facility after second-generation FIV vector-mediated

409 expression of marker genes in anterior segments of human eyes. Investigative ophthalmology \&

$410 \quad$ visual science $43: 3686-3690$.

411 Loewen RT., Brown EN., Roy P., Schuman JS., Sigal IA., Loewen NA. 2016a. Regionally Discrete Aqueous

$412 \quad$ Humor Outflow Quantification Using Fluorescein Canalograms. PloS one 11:e0151754.

413 Loewen RT., Brown EN., Roy P., Schuman JS., Sigal IA., Loewen NA. 2016b. Regionally Discrete Aqueous

$414 \quad$ Humor Outflow Quantification Using Fluorescein Canalograms. PloS one 11:e0151754.

415 Loewen RT., Brown EN., Scott G., Parikh H., Schuman JS., Loewen NA. 2016c. Quantification of Focal

416 Outflow Enhancement Using Differential Canalograms. Investigative ophthalmology \& visual science

$417 \quad \underline{57: 2831-2838 .}$ 
418 Loewen N., Fautsch MP., Peretz M., Bahler CK., Cameron JD., Johnson DH., Poeschla EM. 2001. Genetic

419 modification of human trabecular meshwork with lentiviral vectors. Human gene therapy 12:2109-

$420 \underline{2119}$.

421 Loewen RT., Roy P., Parikh HA., Dang Y., Schuman JS., Loewen NA. 2016d. Impact of a Glaucoma Severity

422 Index on Results of Trabectome Surgery: Larger Pressure Reduction in More Severe Glaucoma. PloS

423 one 11:e0151926.

424 Loewen RT., Roy P., Park DB., Jensen A., Scott G., Cohen-Karni D., Fautsch MP., Schuman JS., Loewen NA.

425 2016e. A Porcine Anterior Segment Perfusion and Transduction Model With Direct Visualization of

426 the Trabecular Meshwork. Investigative ophthalmology \& visual science 57:1338-1344.

427 Loewen RT., Roy P., Park DB., Jensen A., Scott G., Cohen-Karni D., Fautsch MP., Schuman JS., Loewen NA.

428 2016f. A Porcine Anterior Segment Perfusion and Transduction Model With Direct Visualization of

429 the Trabecular Meshwork. Investigative ophthalmology \& visual science 57:1338-1344.

430 Lovelock JE. 1953. The haemolysis of human red blood-cells by freezing and thawing. Biochimica et

$431 \quad$ biophysica acta 10:414-426.

432 Mazur P. 1963. KINETICS OF WATER LOSS FROM CELLS AT SUBZERO TEMPERATURES AND THE LIKELIHOOD

433 OF INTRACELLULAR FREEZING. The Journal of general physiology 47:347-369.

434 Mazur P., Rall WF., Leibo SP. 1984. Kinetics of water loss and the likelihood of intracellular freezing in

435 mouse ova. Influence of the method of calculating the temperature dependence of water

436 permeability. Cell biophysics 6:197-213.

437 McMenamin PG., Steptoe RJ. 1991. Normal anatomy of the aqueous humour outflow system in the

$438 \quad$ domestic pig eye. Journal of anatomy 178:65-77.

439 Micera A., Quaranta L., Esposito G., Floriani I., Pocobelli A., Saccà SC., Riva I., Manni G., Oddone F. 2016.

440 Differential Protein Expression Profiles in Glaucomatous Trabecular Meshwork: An Evaluation Study

441 on a Small Primary Open Angle Glaucoma Population. Advances in therapy 33:252-267. 
442 Neiweem AE., Bussel II., Schuman JS., Brown EN., Loewen NA. 2016. Glaucoma Surgery Calculator:

$443 \quad$ Limited Additive Effect of Phacoemulsification on Intraocular Pressure in Ab Interno Trabeculectomy.

$444 \quad$ Plos one 11:e0153585.

445 Oatts JT., Zhang Z., Tseng H., Shields MB., Sinard JH., Loewen NA. 2013. In vitro and in vivo comparison of

$446 \quad$ two suprachoroidal shunts. Investigative ophthalmology \& visual science 54:5416-5423.

447 Pairwise Alignment Human vs Pig Blast Results. Available at

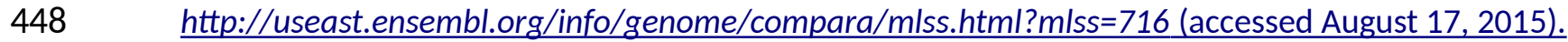

449 Parikh HA., Loewen RT., Roy P., Schuman JS., Lathrop KL., Loewen NA. 2016a. Differential Canalograms

450 Detect Outflow Changes from Trabecular Micro-Bypass Stents and Ab Interno Trabeculectomy.

$451 \quad$ Scientific reports 6:34705.

452 Parikh HA., Loewen RT., Roy P., Schuman JS., Lathrop KL., Loewen NA. 2016b. Differential Canalograms

453 Detect Outflow Changes from Trabecular Micro-Bypass Stents and Ab Interno Trabeculectomy.

$454 \quad$ Scientific reports 6:34705.

455 Pattabiraman PP., Rinkoski T., Poeschla E., Proia A., Challa P., Rao PV. 2015. RhoA GTPase-induced ocular

456 hypertension in a rodent model is associated with increased fibrogenic activity in the trabecular

457 meshwork. The American journal of pathology 185:496-512.

458 Peters JC., Bhattacharya S., Clark AF., Zode GS. 2015. Increased Endoplasmic Reticulum Stress in Human

$459 \quad$ Glaucomatous Trabecular Meshwork Cells and Tissues. Investigative ophthalmology \& visual science

$460 \quad \underline{56: 3860-3868 .}$

461 Roy P., Loewen RT., Dang Y., Parikh HA., Bussel II., Loewen NA. 2017. Stratification of phaco-trabectome

462 surgery results using a glaucoma severity index in a retrospective analysis. BMC ophthalmology

$463 \quad \underline{17: 30 .}$

464 Ruiz-Ederra J., García M., Martín F., Urcola H., Hernández M., Araiz J., Durán J., Vecino E. 2005.

465 Comparison of three methods of inducing chronic elevation of intraocular pressure in the pig

466 (experimental glaucoma). Archivos de la Sociedad Espanola de Oftalmologia 80:571-579. 
467 Saccà SC., Pulliero A., Izzotti A. 2015. The dysfunction of the trabecular meshwork during glaucoma

$468 \quad$ course. Journal of cellular physiology 230:510-525.

469 Saenz D., Barraza R., Loewen N., Teo W., Kemler I., Poeschla E. 2007. Production and Use of Feline

$470 \quad \underline{\text { Immunodeficiency Virus (FIV)-Based Lentiviral Vectors. In: Friedmann T, Rossi JJ eds. Gene Transfer: }}$

471 Delivery and Expression of DNA and RNA : a Laboratory Manual. CSHL Press, 57-73.

472 Sanchez I., Martin R., Ussa F., Fernandez-Bueno I. 2011. The parameters of the porcine eyeball. Graefe's

473 archive for clinical and experimental ophthalmology = Albrecht von Graefes Archiv fur klinische und

474 experimentelle Ophthalmologie 249:475-482.

475 Suárez T., Vecino E. 2006. Expression of endothelial leukocyte adhesion molecule 1 in the aqueous

476 outflow pathway of porcine eyes with induced glaucoma. Molecular vision 12:1467-1472.

477 Torrejon KY., Papke EL., Halman JR., Stolwijk J., Dautriche CN., Bergkvist M., Danias J., Sharfstein ST., Xie Y.

$478 \quad 2016$. Bioengineered glaucomatous 3D human trabecular meshwork as an in vitro disease model.

$479 \quad$ Biotechnology and bioengineering 113:1357-1368.

480 Tripathi RC. 1971. Ultrastructure of the exit pathway of the aqueous in lower mammals:(A preliminary

481 report on the "angular aqueous plexus"). Experimental eye research 12:311-314.

482 Wang C., Dang Y., Waxman S., Xia X., Weinreb RN., Loewen NA. 2017. Angle stability and outflow in dual

483 blade ab interno trabeculectomy with active versus passive chamber management. PloS one

$484 \quad$ 12:e0177238.

485 Wolkers WF., Balasubramanian SK., Ongstad EL., Zec HC., Bischof JC. 2007. Effects of freezing on

486 membranes and proteins in LNCaP prostate tumor cells. Biochimica et biophysica acta 1768:728-

$487 \quad \underline{736}$.

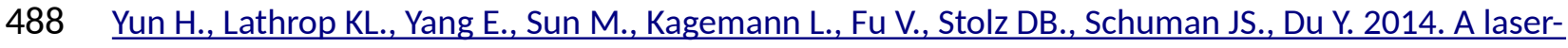

489 induced mouse model with long-term intraocular pressure elevation. PloS one 9:e107446. 
490 Yun H., Zhou Y., Wills A., Du Y. 2016. Stem Cells in the Trabecular Meshwork for Regulating Intraocular 491 Pressure. Journal of ocular pharmacology and therapeutics: the official journal of the Association for 492 Ocular Pharmacology and Therapeutics 32:253-260.

493 Zhang Z., Dhaliwal AS., Tseng H., Kim JD., Schuman JS., Weinreb RN., Loewen NA. 2014. Outflow tract 494 ablation using a conditionally cytotoxic feline immunodeficiency viral vector. Investigative 495 ophthalmology \& visual science 55:935-940.

496 Zhu W., Gramlich OW., Laboissonniere L., Jain A., Sheffield VC., Trimarchi JM., Tucker BA., Kuehn MH. 497 2016. Transplantation of iPSC-derived TM cells rescues glaucoma phenotypes in vivo. Proceedings of 498 the National Academy of Sciences of the United States of America. DOI: 10.1073/pnas.1604153113. 
A

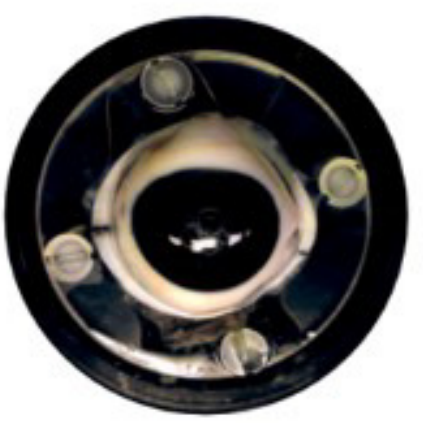

C

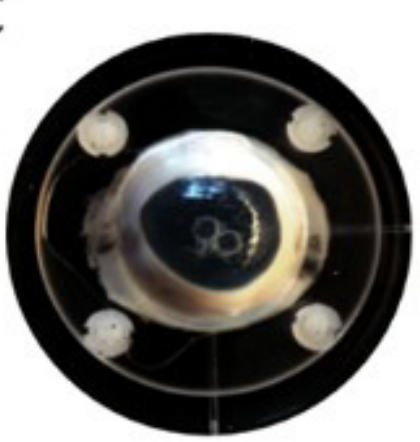

E

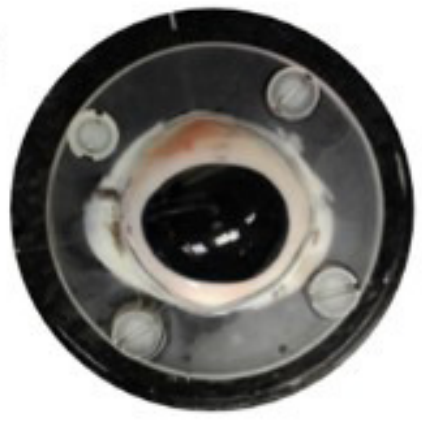

B
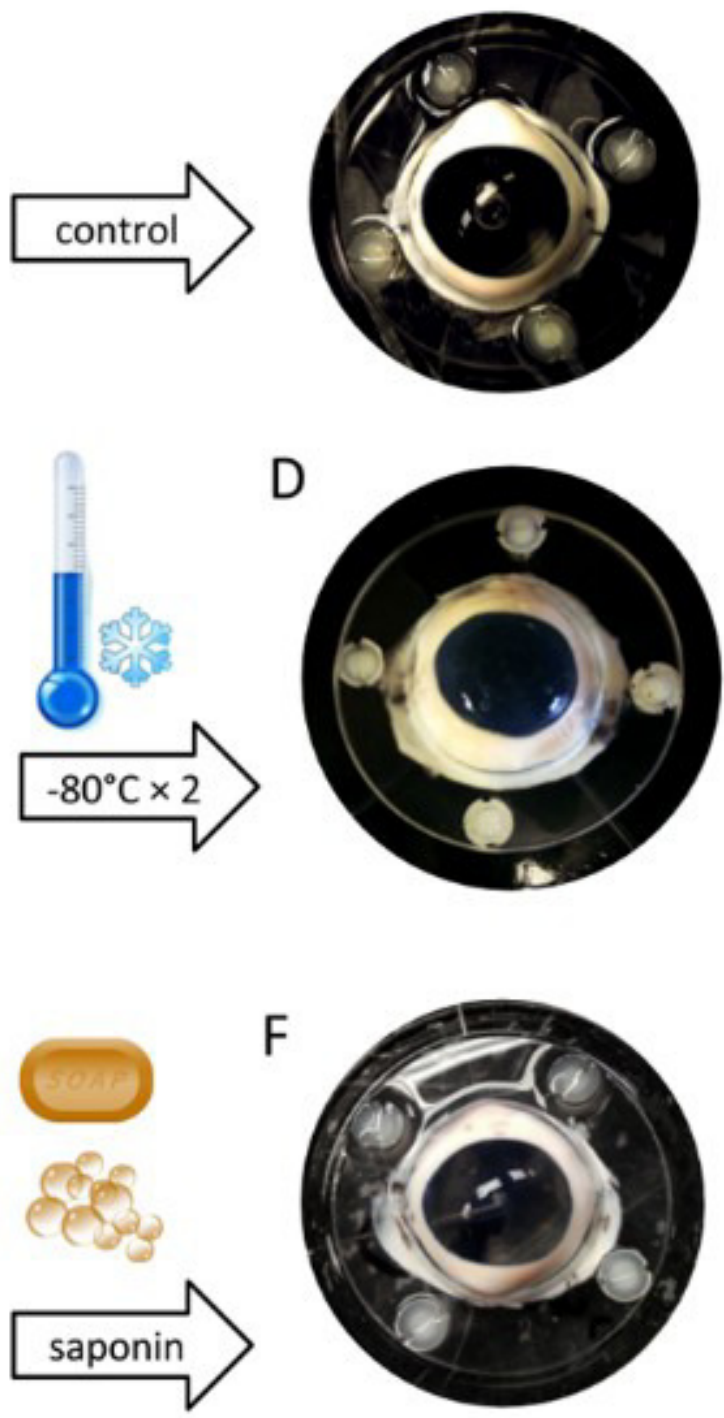

$\mathrm{F}$

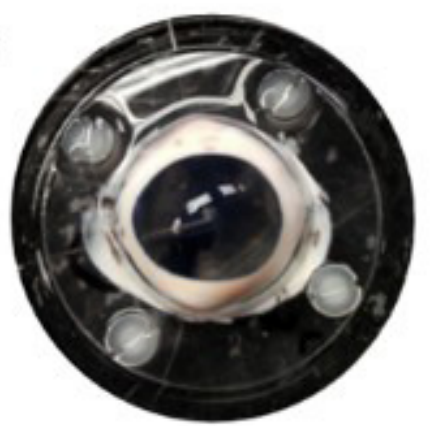

500 Figure 1: Freeze-thaw treatment of anterior segment cultures. Eyes were exposed to two cycles 501 of freezing at $-80^{\circ} \mathrm{C}$ followed by thawing at room temperature. The macroscopic appearance 502 remained mostly unchanged. 

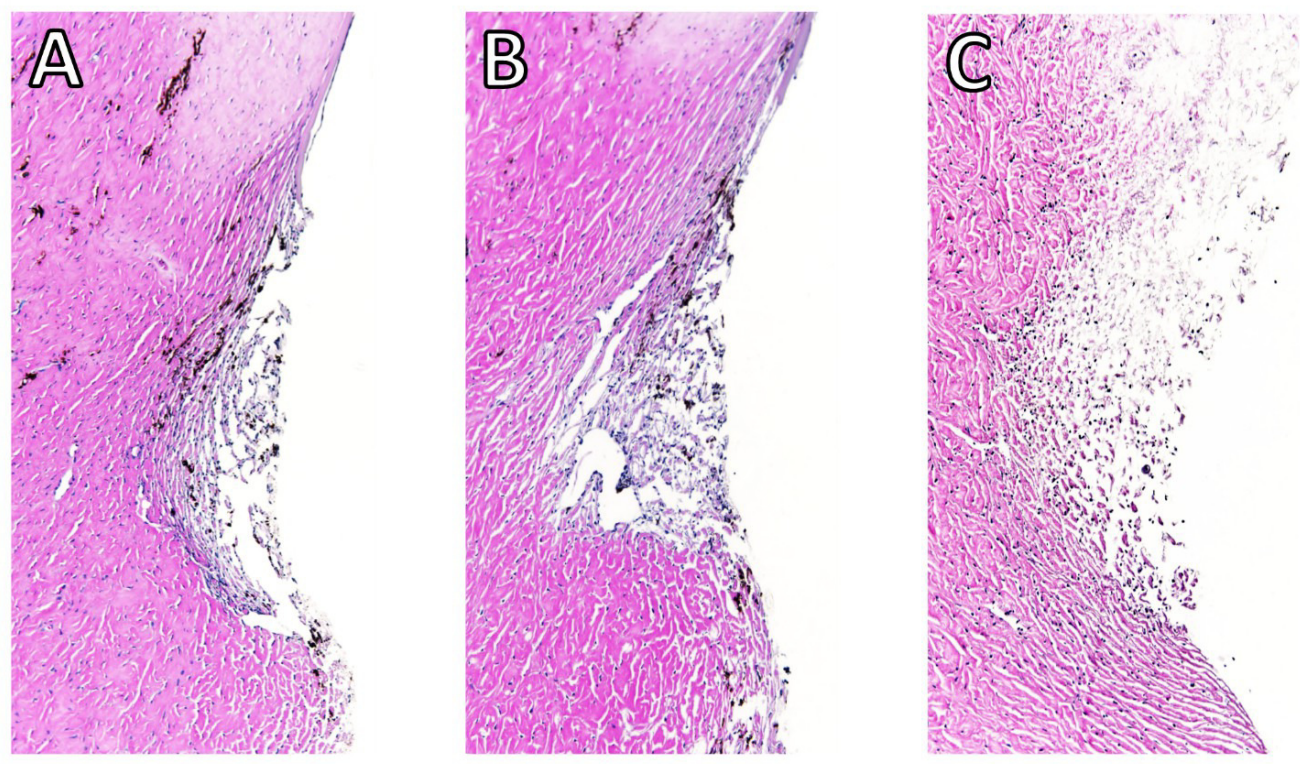

503 Figure 2. Histology of the angle of perfused anterior chambers. Control eyes (A) had an

504 appearance that was similar to that of freeze-thaw treated eyes (B). Saponin-treated eyes (C) 505 presented with a less compact structure. Blue nuclei could be seen in all sections. 

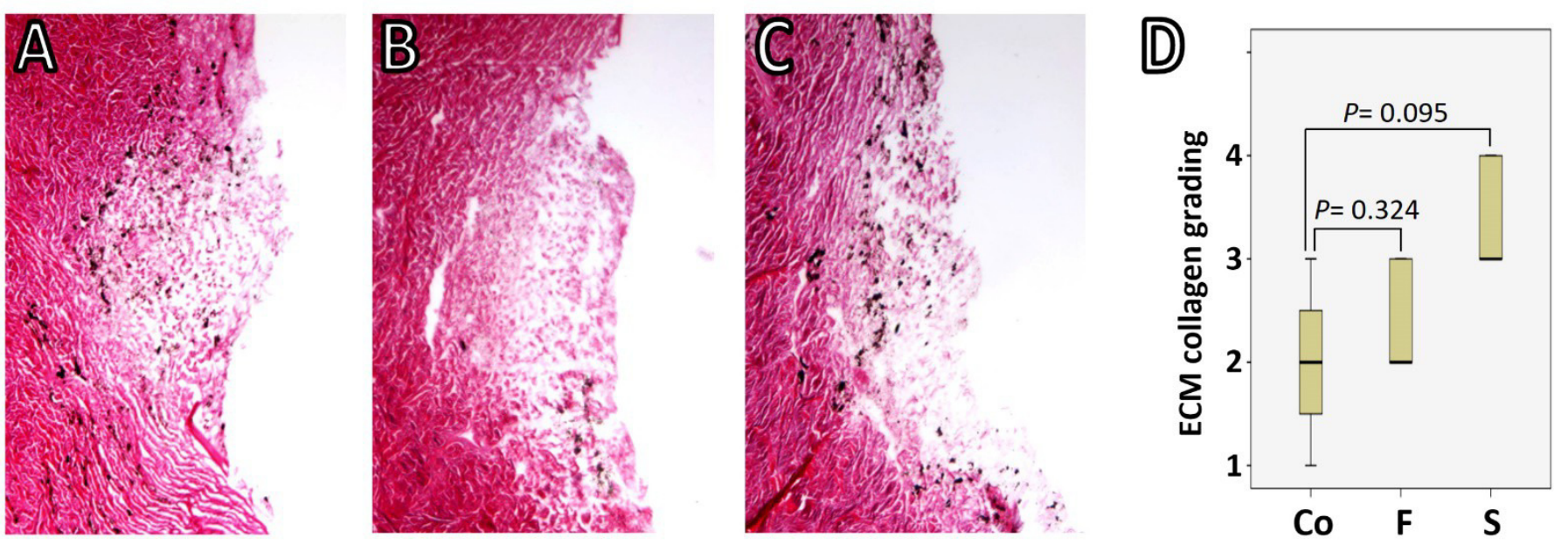

506 Figure 3. TM-ECM assessment by collagen staining. Total collagen was stained with Picro Sirius

507 Red and scored by a masked observer (Yalong Dang) from 1 to 4 according to the staining

508 intensity. Collagen deposition in the normal control $(A)$ is comparable to that in either freeze-

509 thaw group (B) or saponin-treated group (C) after 180 hours perfusion $(P=0.324$ and $P=0.095$,

510 respectively)(D). 

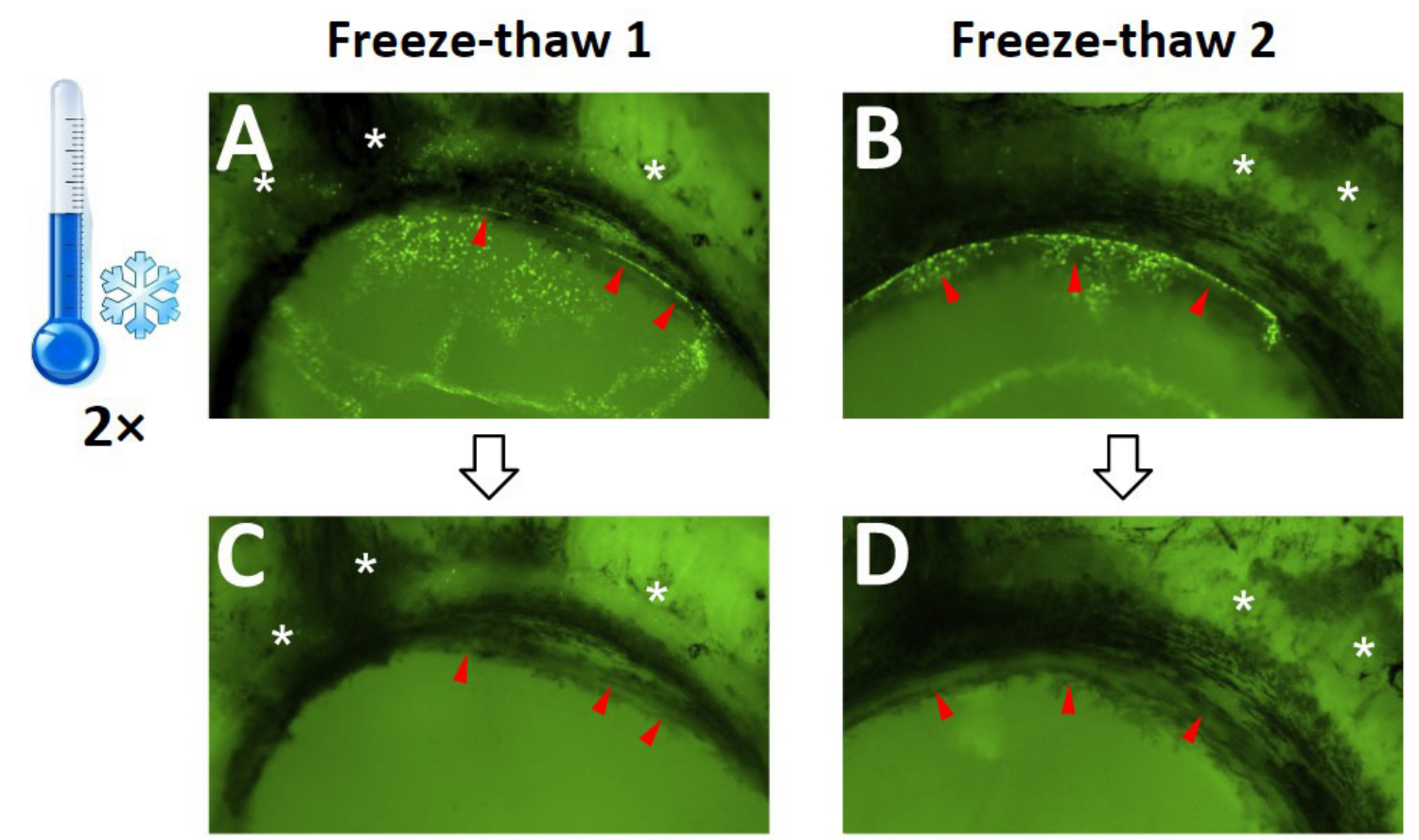

Saponin 1
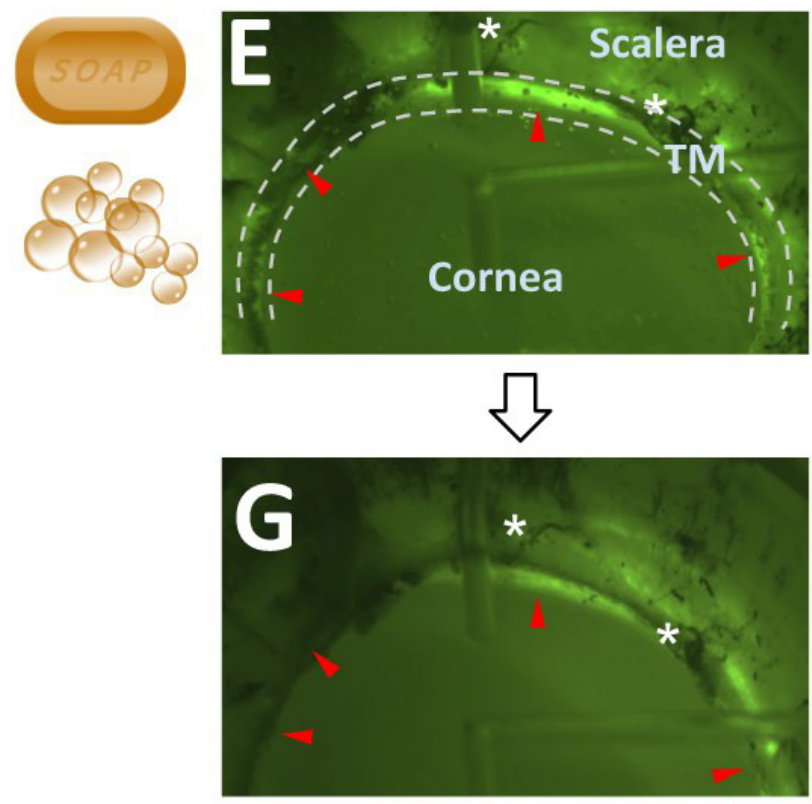

Saponin 2
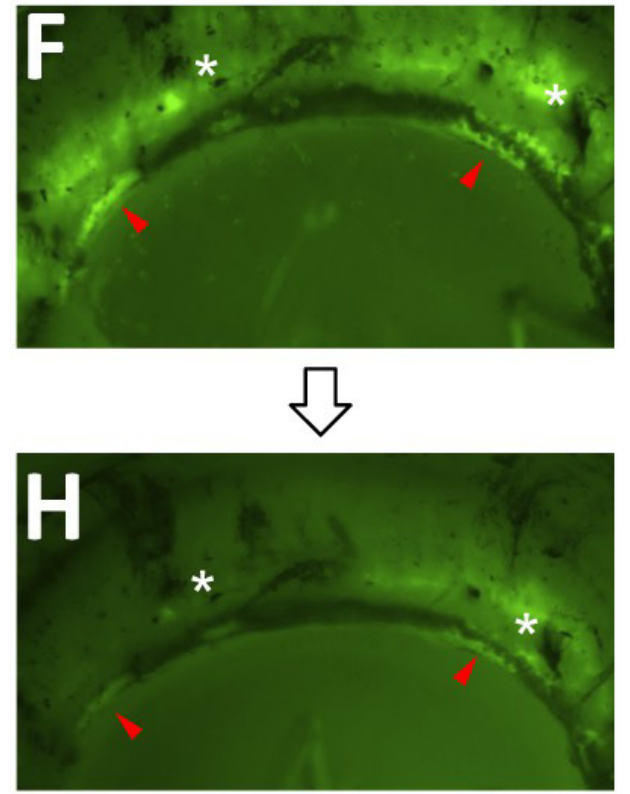

511 Figure 4: Confirmation of cytoablation. EGFP expression of GINSIN transduced cells ( $A$ and $B$ ) 512 vanished after two freeze-thaw cycles ( $C$ and $D)$. In contrast, eGFP could still be seen in saponin513 treated eyes ( $G$ and $H$ ). Red arrowheads point to transduced trabecular meshwork (TM)

514 (between dash lines) that was ablated after freeze-thaw. Sclera, cornea and TM are labeled in 515 the first saponin ablated eye (E). The black lines are pigmented areas of the scleral spur and 
516 sclera where the ciliary body attached. Asterisks are placed near landmarks to make it easier to

517 compare the before and after treatment images.

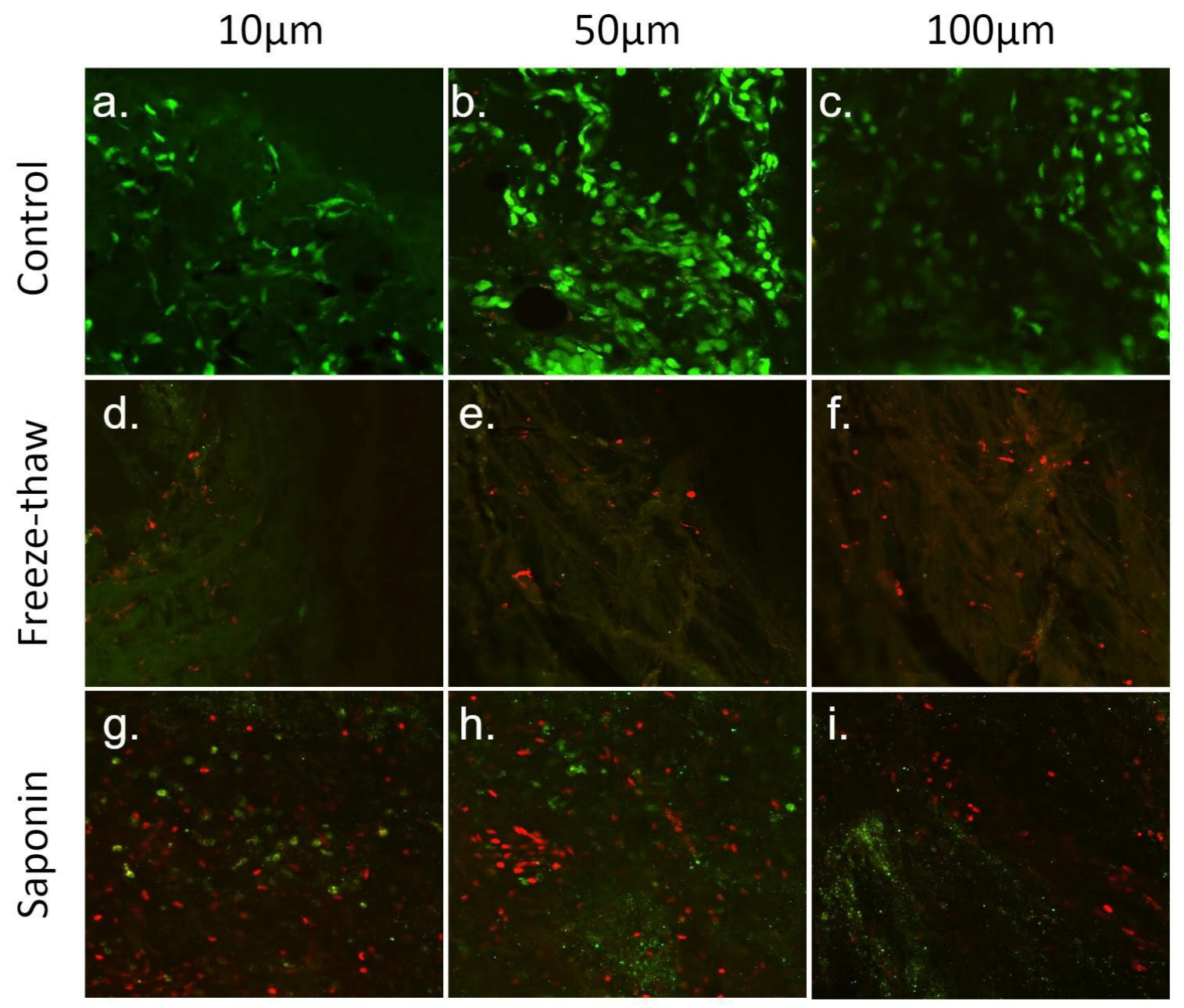

518 Figure 5. Assessment of TM cell viability by calcein AM/PI co-labelling. Viable trabecular

519 meshwork (TM) cells exposed to calcein AM showed bright green fluorescence, while dead TM

520 cells allowed PI to enter cell membrane and label the cell nuclear with red fluorescence. In the

521 control group, most TM cells were still viable after perfusion for two weeks (Fig. 5a- Fig. 5c). In

522 contrast, cells, including many nuclei, were destroyed by freeze-thaw. No calcein AM, and only a

523 few PI-labeled TM cells were found (Fig.5d- Fig. 5f). Different from the other two groups, a few

524 TM cells were still alive in the saponin-treated group, but most of them were labeled as dead

525 cells by PI (Fig. 5g- Fig. 5i). The different microscopy depths are approximate samples from the

526 uveal (left), corneoscleral (middle) and cribriform layer (right) in this flat mount. 


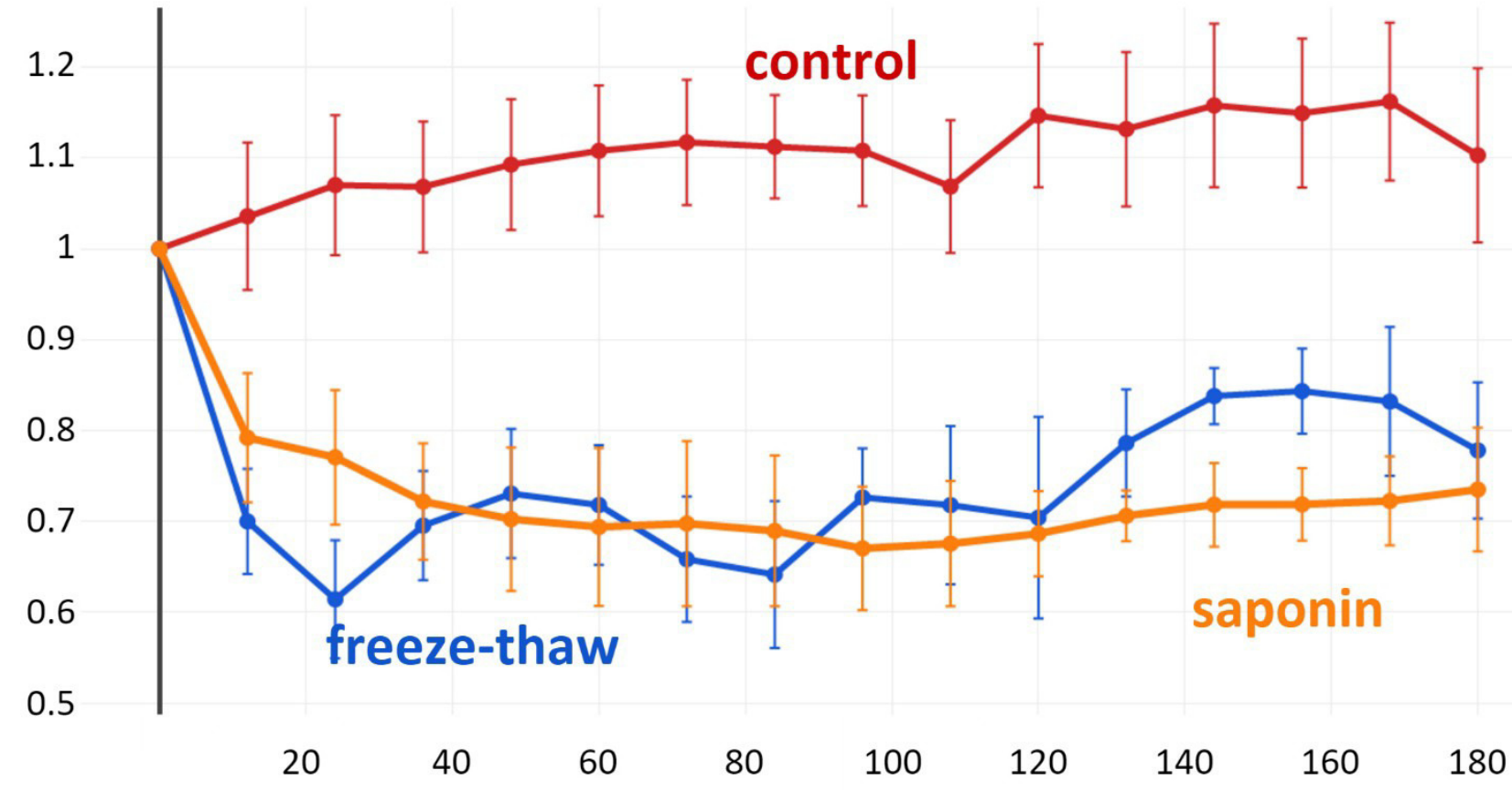

527 Figure 6. IOP Reduction after TM decellularization. Freeze-thaw (F) resulted in a more rapid IOP

528 reduction than saponin $(S)$ (averages \pm SEM). There were no differences at any single time 529 between $\mathrm{F}$ and S. Differences between controls and S were not significant onward from 96 530 hours. 